\title{
A CASE OF CHONDRODYSTROPHIA CALCIFICANS CONGENITA
}

\author{
BY
}

\author{
SHEILA SINGH PAUL, P. L. RAO, P. MULLICK and P. KALLIANA \\ From the Department of Paediatrics, Kalavati Saran Children's Hospital, \\ Lady Hardinge Medical College and Hospital, New Delhi, India
}

(RECEIVED FOR PUBLICATION MAY 28, 1963)

Chondrodystrophia calcificans congenita was first reported by Conradi in 1914 as chondrodystrophia foetalis hypoplastica, at which time it was thought to be an atypical form of achondroplasia. It is a rare form of chondrodystrophy (Nelson, 1959). Fairbank in 1927 described two cases under the title 'dysplasia epiphysialis punctata'. Congenital stippled epiphyses is suggested as a better term by Jeune, Larbre, Carron and Couette (1953) for the reason that chondrodystrophy is present in some of the cases but stippled epiphyses are found in all the cases.

The aetiology is obscure: it occurs sporadically and occasionally shows a familial tendency (Caffey, 1961 ; Jeune et al., 1953). Consanguinity has been observed in some of the reported cases: a Mendelian recessive mode of transmission is thought to be the most likely. Maternal illness during pregnancy has been noticed in some of the cases. It is more common in prematures, and female children are affected three times as often as male (Sheach and Middlemiss, 1956), though Wenzl, Ivins and Stickler (1961) noticed an equal sex distribution. The thyroid as a possible aetiological factor was suggested in six cases (Wenzl et al., 1961). Some believe that a metabolic disorder is responsible as the condition is associated with bilateral cataract (Yakovac, 1954).

The condition is recognized clinically in the first few months or later in life. No record of a case reaching adult life can be found in the literature. The disorder is congenital, affecting mainly cartilage, muscle and eyes. In the very early months it may be an accidental diagnosis (Wenzl et al., 1961). These infants are dwarfs due to rhizomelia with severe shortening of humeri and femora, the former more than the latter. There is an asymmetry of involvement which is unlike the symmetry of achondroplasia. One limb involvement has been described as dysplasia epiphysialis punctata mono- melia. Flexion deformities of the limbs are due to muscle fibrosis involving commonly the knees and elbows. Limitation of movements of the joints are due to defects in articulation of the bones. Occasionally this is accompanied by pain and swelling. These infants are mostly weak, fail to thrive, are subject to infections and are often mentally defective. Associated anomalies may be seen such as polydactyly, syndactyly, brachydactyly, congenital dysplasia of the hips, vertebral wedging, kyphosis, high arched palate, saddle nose, cleft palate, cretinoid facies, mongolism, umbilical and inguinal hernia and abnormalities of the cardiovascular and genitourinary system (Josephson and Oriatti, 1961). Dyskeratotic types of skin changes with dryness, seborrhoeic dermatitis and icthyotic hyperkeratosis, incontinentia pigmenti and pilonidal cyst (Josephson and Oriatti, 1961) are shown by $25 \%$ of the cases. Bilateral congenital cataracts are reported by Josephson and Oriatti in one-third of the cases, and in nine out of the 42 studied by Mosekilde (1952). Cataracts may be seen at birth or delayed till $4 \frac{1}{2}$ months or later (Josephson and Oriatti, 1961). Bilateral optic atrophy with or without cataracts has also been reported (Josephson and Oriatti, 1961).

No significant biochemical changes have been noted.

The characteristic histological change is the focal deposition of lime in masses of degenerating connective tissue in the growing cartilage of both primary and secondary ossification centres (Wenzl et al., 1961). The epiphysial cartilage and the endochondral bone cartilage are well vascularized, there is mucoid degeneration with cartilage fragmentation and cyst formation, but whether the primary defect is vascular or cartilagenous is not known. The mucoid degeneration and calcification are not necessarily related. Calcification is followed by breakdown, and removal is affected by fibro- 
vascular tissue (Josephson and Oriatti, 1961). The lens and cartilage have a high content of mucopolysaccharide, lack an intrinsic blood supply and carry on metabolic activity by a process of diffusion (Yakovac, 1954).

Of the cases, $50 \%$ die of intercurrent infection before 1 year of age (Lane, 1960). Two clinical forms are recognized. A severe type with marked generalized epiphysial involvement associated with other abnormalities. Cataracts in particular indicate a poor prognosis. The condition terminates in death from overwhelming pulmonary and renal infection by 2 years of age. In a less severe variety in which the lesion is limited to a single epiphysis or to one extremity with or without associated abnormalities, the prognosis is good: these children may be left with a residual deformity that needs corrective orthopaedic therapy years later.

From a survey of the published reports only four cases have been followed beyond $4 \frac{1}{2}$ years. Selakovich and White (1955) report a case with monomelic involvement followed for 11 years, which resulted in shortening and hypoplasia of that limb: Fairbank (1949) and Paul (1954) each followed their cases for 9 years, and Wenzl et al. (1961) followed a case for $\mathbf{8}$ years and 3 months. All these cases were left with shortening of the limbs. Very few cases reach adulthood. Perhaps milder cases may not be reported or not recognized and thus the prognosis is undoubtedly better.

\section{Radiological Findings}

The characteristic radiological feature is the premature deposition of numerous, discrete, punctate calcific densities in the region of the developing epiphyses or preformed cartilage. The stippled densities are present before the normal time of appearance of the ossification centres. Occasionally stippling may surround a normal epiphysis or replace the epiphyses. The epiphyses of the proximal end of the tibia, the femur, humerus, the distal end of the tibia, the radius and ulna and both proximal and distal ends of the fibula are often involved. Epiphyses about the elbow are commonly involved in contradistinction to almost all the other dysplasias. The sacrum, entire vertebral column, posterior ends of ribs and occasionally the acetabulum, ischium, sternum, scapula, tarsal and carpal bones, patella, hyoid bone, thyroid, larynx and tracheal rings may also be affected. Joint spaces and synovial membranes are not exempt from stippling. The long bones are often short and thick with splayed ends and irregular epiphysial lines. The proximal long bones, femora and humeri are severely shortened. The joint spaces appear large due to large non-ossified epiphyses. The vertebral column shows wedging or even platyblasia with kyphosis as in Morquio's disease. Some of the longstanding extensive cases of coronal cleft vertebra have been included in this condition. The cruciate segmental appearance of the vertebral bodies is suggestive of notochordal remnants. Later the multiple stippling of the epiphyses tends to fuse into single, smooth, flattened, well-outlined but deformed epiphyses (Lane, 1960).

\section{Case Report}

A male baby Bittu was born normally on February 5 , 1963, and admitted on March 22, 1963, to this hospital for flexion deformities of both knee and elbow joints, which had been present since birth (Figs. 1, 2 and 3). The 18-year-old mother had upper respiratory infection at the fifth and seventh months of pregnancy. The father, 35 years of age, was healthy. No consanguinity was noted. There was no history of congenital abnormalities in the family.

On examination the baby was well nourished, weight $2,520 \mathrm{~g}$., length $45 \mathrm{~cm}$.; skull $33 \mathrm{~cm}$. The skin of the cheeks and chin was rough, erythematous and scaling. There was no cyanosis. Pulse rate 156 per minute, respirations 48 per minute. The heart was not enlarged;

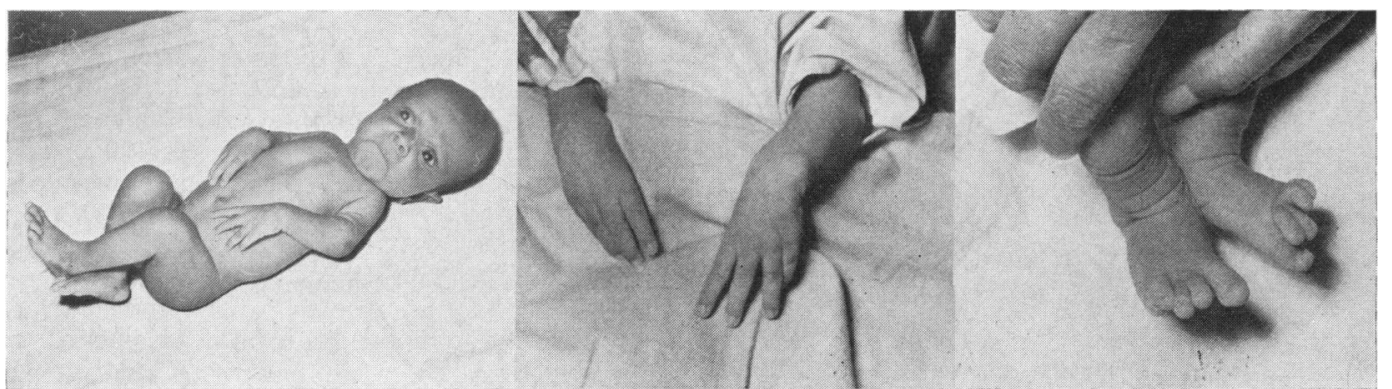

FIGS. 1, 2 and 3.-Clinical photographs showing flexion deformities of both elbows and wrists. Note the equal length of second and third fingers and second and third toes on both sides. 


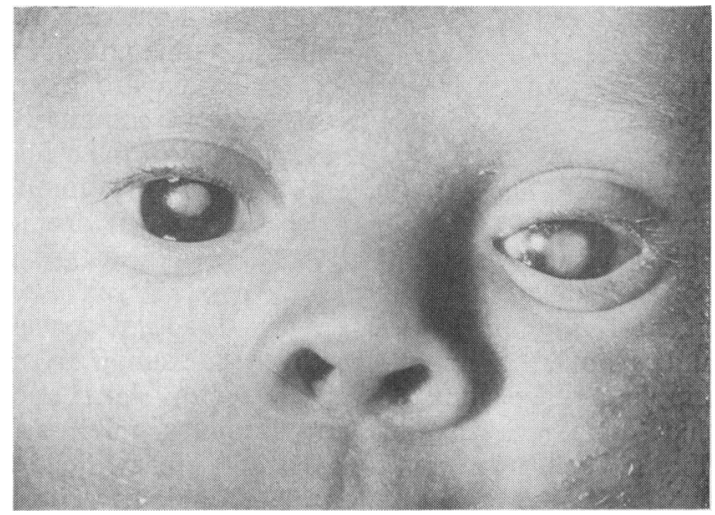

FIG. 4.-Clinical photograph of eyes showing congenital bilateral cataract.

both sounds were normal. A systolic murmur was best heard in the third and fourth interspaces. Both eyes had cataracts. On dilating the pupil the left eye showed a large cataract filling the pupillary aperture (Fig. 4). The right eye had a cataractous lens which was displaced upwards. The red reflex could be seen through the aphakic portion. No details of the fundi could be made out. In the upper limbs the elbows reached down to the level of the nipple line. Both elbows and wrists were flexed at 30 degrees, but the latter could be passively fully extended. The thumbs were directed across the palm towards the ring fingers and the index and the middle fingers were of the same size. In the lower limbs the hips could not be abducted more than 20 degrees and could not be extended The fourth and fifth toes of both feet were very short in length. Investigations revealed a serum calcium $7.9 \mathrm{mg} . / 100 \mathrm{ml}$; $\mathrm{Hb} 13.5 \mathrm{~g}$., red blood cells 3.95 million/c.mm., white blood cells $9,300 / \mathrm{c} . \mathrm{mm}$. Mother and baby were both $\mathrm{Rh}$ positive.

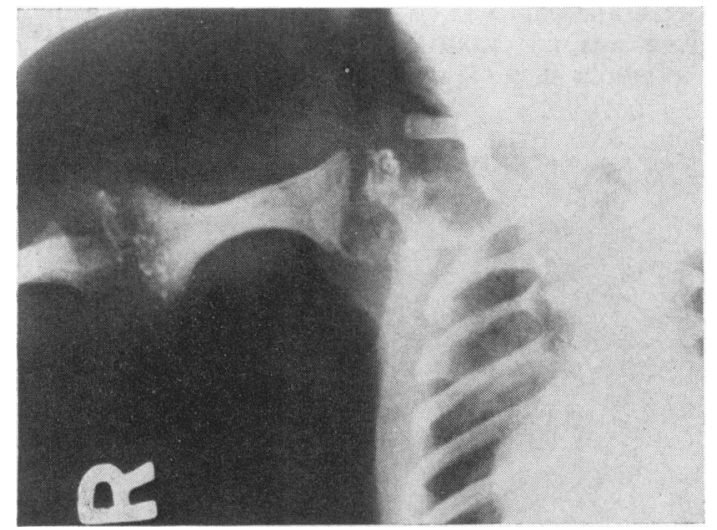

FIG. 5.-Skiagram of right humerus showing the stippled epiphyses of both upper and lower ends. Note shortening of humerus. The left humerus also showed similar changes.

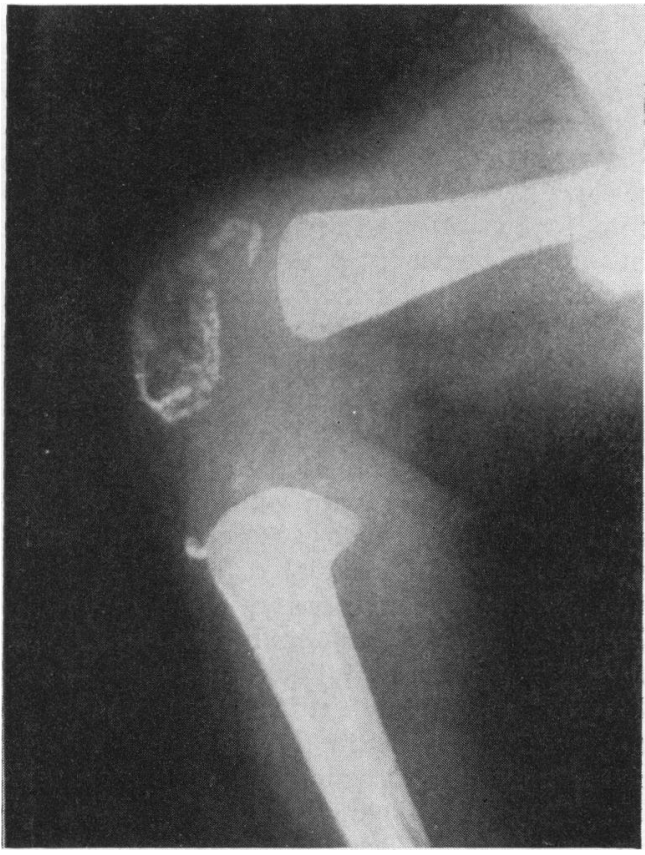

FIG. 6.-Skiagram of lateral view of knee joint showing clearly the punctate stippling.

X-ray Reports. (1) Antero-posterior view of chest shows lung fields clear. Cardiac size and contour are not remarkable except for a questionable right ventricular dilatation. The ends of both humeri and the lower cervical and upper dorsal vertebrae show discrete punctate stippling.

(2) Antero-posterior view of upper extremities shows characteristic stippling present at both ends of humeri and the distal ends of both radii (Fig. 5). The humeri are short with flaring of the proximal and distal ends.

(3) Antero-posterior view of pelvis and lower extremities shows bilateral stippling around the hip joints, knee joints (Fig. 6) and ankle joints. The ischium shows similar changes. Both femora are shortened and the ends are flared.

(4) Lateral view of the lower extremities shows stippling in the calcaneum as well.

(5) Lateral view of skull shows that the bones of the cranial vault are normal. The lower cervical and upper dorsal vertebrae show the stippled appearance seen in the other bones.

\section{Summary}

A case of chondrodystrophia calcificans congenita is reported. The baby had typical radiological findings, bilateral cataract, flexion of elbows and knees and deformities of fingers and toes. 
We wish to express our appreciation to Dr. S. Kurup, Ophthalmologist, Lady Hardinge Medical College and Hospital, for confirming our findings. We thank Prof. M. Chaudhuri, Principal, Lady Hardinge Medical College and Member-Secretary, Kalavati Saran Children's Hospital, for permission to publish this paper.

\section{REFERENCES}

Caffey, J. (1961). Pediatric X-Ray Diagnosis, 4th ed., p. 885. Year Book Medical Publishers, Chicago.

Conradi, E. (1914). Vorzeitiges Auftreten von Knochen- und eigenartigen Verkalkungskernen bei Chondrodystrophia fötalis hypoplastica. Histologische und Röntgenuntersuchungen. $J b$. Kinderheilk., 80, 86.

Fairbank, H. A. T. (1927). Some general diseases of the skeleton. Brit. J. Surg., 15, 120

- (1949). An atlas of general affections of the skeleton. 8 . Dysplasia epiphysialis punctata. Synonyms-stippled epiphyses, chondrodystrophia calcificans congenita. Hunermann. J. Bone Jt Surg., 31B, 114.
Jeune, M., Larbre, F., Carron, R. and Couette, I. (1953). La maladie congénitale des épiphyses pointillées. Arch. franc. Pediat., $10,914$.

Josephson, B. M. and Oriatti, M. D. (1961). Chondrodystrophia calcificans congenita. Pediatrics, 28, 425.

Lane, J. W. (1960). Roentgenographic manifestations of the cartilaginous dysplasias. Amer. J. med. Sci., 240, 636.

Mosekilde, E. (1952). Stippled epiphyses in the newborn and in infants. Acta radiol. (Stockh.), 37, 291.

Nelson, W. E. (1959). Textbook of Pediatrics, 7th ed., p. 1237. Saunders, Philadelphia.

Paul, L. W. (1954). Punctate epiphyseal dysplasia (Chondrodystrophia calcificans congenita). Report of case with 9 year period of observation. Amer. J. Roentgenol., 71, 941.

Selakovich, W. G. and White, J. W. (1955). Chondrodystrophia calcificans congenita. Report of a case. J. Bone Jt Surg., 37A, 1271.

Sheach, J. M. and Middlemiss, J. H. (1956). Dysplasia epiphysialis punctata. Brit. J. Radiol., 29, 111.

Wenzl, J. E., Ivins, J. C. and Stickler, G. B. (1961). Punctate epiphyseal dysplasia, another cause of leg length inequality. $J$. Pediat., 59, 390.

Yakovac, W. C. (1954). Calcareous chondropathies in the newborn infant. Arch. Path., 57, 62. 